\section{Pendekatan Technology Acceptance Model dalam Analisis Penerimaan Teknologi (Studi Kasus pada Pengguna Mobile Payment)}

\section{Lusia Permata Sari Hartanti}

Program Studi Teknik Industri, Universitas Katolik Widya Mandala Surabaya

$\bowtie$ lusia.hartanti@ukwms.ac.id

\section{Pendahuluan}

Perkembangan teknologi mengakibatkan terjadi perubahan di berbagai aspek. Perkembangan ini muncul karena adanya kebutuhan dari manusia. Salah satu perubahan yang dirasakan adalah di aspek keuangan, yaitu muncul financial technology (finTech). FinTech dimanfaatkan oleh berbagai kalangan sebagai layanan keuangan untuk pembayaran, transfer, pengolahan dana, deposit dana dan sebagainya (Sianipar, 2017). FinTech merupakan penggabungan teknologi dengan jasa keuangan sehingga terjadi perubahan model bisnis menjadi digital. Pada model bisnis konvensional maka proses pembayaran dilakukan secara bertatap-muka dan membawa sejumlah uang tunai, namun dengan adanya perkembangan teknologi maka cara ini mulai beralih. Transaksi tidak hanya dilakukan dalam jarak dekat, namun jarak jauhpun dapat dilakukan tanpa harus saling bertatap muka.

Banyak hal yang mendorong perkembangan FinTech, antara lain kemajuan perangkat mobile, promosi dan pelayanan yang ditawarkan kepada pengguna, serta perubahan gaya hidup. Lebih lanjut
Perkembangan teknologi yang semakin pesat mendorong terjadinya perubahan di berbagai aspek, salah satunya adalah aspek keuangan. Transaksi yang dulu dilakukan secara konvensional mulai beralih ke arah digital dengan mobile payment. Technology Acceptance Model (TAM) adalah salah satu model yang sering digunakan untuk menjelaskan penerimaan teknologi. Penelitian ini bertujuan untuk menguji teori TAM dalam menilai penerimaan pengguna mobile payment dan menjelaskan faktor-faktor yang mempengaruhi pengguna dengan metode Partial Least Square (PLS). Penelitian ini menggunakan data primer berupa kuesioner yang disebarkan kepada responden. Hasil Evaluasi Outer Model dan Inner Model menunjukkan bahwa model fit dengan data atau dapat menggambarkan fenomena/realitas di lapangan. Selain itu hasil pengujian hipotesis menunjukkan attitude toward using pengaruh signifikan terhadap behavior intention to use, perceived ease of use berpengaruh signifikan terhadap attitude toward using, perceived ease of use berpenga ruh signifikan terhadap perceived usefulness, perceived usefulness berpengaruh signifikan terhadap attitude toward using, perceived usefulness berpengaruh signifikan terhadap behavior intention to use.

Kata kunci: Technology Acceptance Model, penerimaan teknologi, mobile payment, Partial Least Square

Diajukan: 5 November 2020

Direvisi: 10 Desember 2020

Diterima: 15 Desember 2020

Dipublikasikan online: 25 Januari 2021 diungkapkan oleh Ernst and Young (2011), peningkatan penggunaan pembayaran non-tunai diakibatkan oleh peningkatan penggunaan perantara mobile.

Mobile Payment (m-payment), diartikan sebagai suatu pembayaran dimana terjadi transfer dana dengan menggunakan ponsel dan dapat dilakukan dimanapun sebagai imbalan atas barang atau jasa (Untoro, 2013). M-payment dibagi menjadi tiga kategori yaitu mobile commerce, mobile acceptance, dan mobile wallet (Morgan, 2013). Gambar 1 menunjukkan perkembangan peluncuran berbagai m-payment di Indonesia, sedangkan Gambar 2 menunjukkan jumlah pengguna mobile payment berdasarkan MDI Ventres dan Mandiri Sekuritas Research tahun 2018. GoPay dan OVO merupakan layanan financial technology terbesar di Indonesia saat ini (Laucereno, 2019).

Technology Acceptance Model (TAM) merupakan suatu model yang dapat menjelaskan penerimaan atau penggunaan teknologi. TAM yang diadaopsi dari TRA digunakan untuk menyelidiki determinan penerimaan Sistem Informasi (SI) yang memiliki dua faktor utama yaitu manfaat yang dirasakan dan kemudahan peggunaan yang dirasakan (Davis, 1986). Melalui TAM dapat diperoleh pemahaman yang lebih baik mengenai

Cara mensitasi artikel ini:

Lusiana P.S. H (2021). Pendekatan Technology Acceptance Model dalam Analisis Penerimaan Teknologi (Studi Kasus pada Pengguna Mobile Payment). Buletin Profesi Insinyur 4(1) 001-006 
perilaku pengguna dalam menggunakan teknologi. TAM didasarkan pada dua konsep dasar, perceived usefulness dan perceived ease of use, yang memprediksi niat perilaku untuk menggunakan dan penggunaan teknologi baru yang sebenarnya (Phonthanukitithaworn, et al., 2016; Taejung Kim dan Weisheng Chiu, 2018; Flavian dan Guinaliu, 2020).

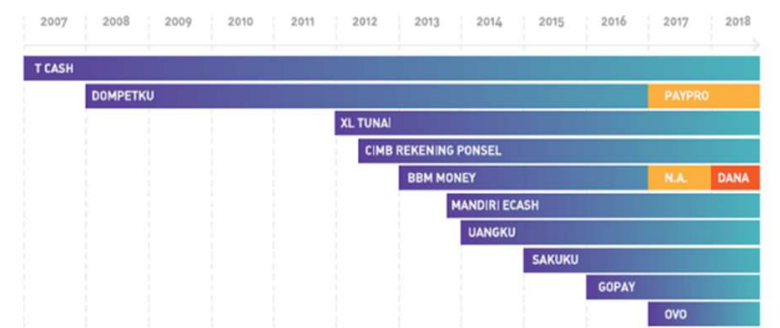

Gambar 1 Perkembangan Peluncuran Berbagai $M$ Payment Di Indonesia

(Sumber: MDI Ventures dan Mandiri Sekuritas Research, 2018)

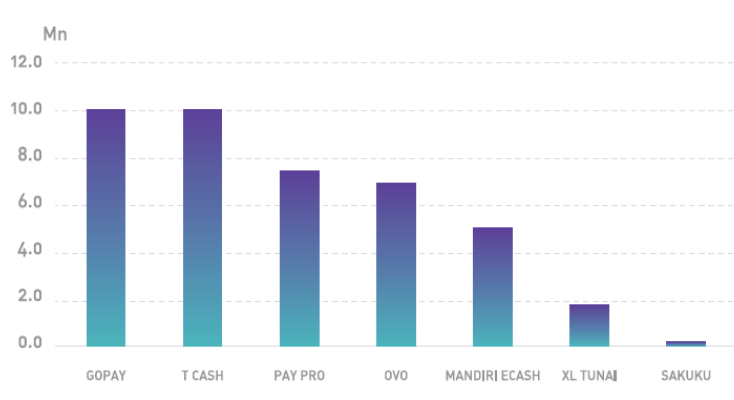

Gambar 2 Jumlah Pengguna Mobile Payment (Sumber: MDI Ventures dan Mandiri Sekuritas Research, 2018)

Dalam perkembangannya, TAM telah banyak dimodifikasi untuk memprediksi perilaku adopsi teknologi karena banyaknya faktor tambahan yang dapat mempengaruhi, penerimaan teknologi dalam konteks tertentu (Flavian dan Guinaliu, 2020). LiébanaCabanillas et al. (2014) menyebutkan tiga variabel yang digunakan dalam TAM yaitu ease of use, perceived usefulness dan attitude. Dalam penelitian ini, ditambahkan variabel lainnya berupa behavior intention to use, yang diadopsi dari Theory of Reasoned Action (TRA) sehingga diharapkan dapat meningkatkan daya prediksi TAM. TRA merupakan model yang menjelaskan suatu perilaku individu berdasarkan hubungan antara variabel beliefs-attitude-intention-behaviori (LiébanaCabanillas et al., 2014)

Masih banyak model lain yang digunakan untuk menganalisis penerimaan teknologi, yaitu uses and gratification atau diffusion of innovation, namun TAM dapat dimodifikasi sesuai faktor-faktor yang diperlukan pada adopsi penerimaan pengguna (Shin, 2009). Bailey et al., (2017) mengungkapkan TAM dapat menjelaskan faktor yang mendorong penerapan teknologi.

Penelitian ini bertujuan untuk menguji teori TAM dalam menilai penerimaan pengguna mobile payment dan menjelaskan faktor-faktor yang mempengaruhi pengguna dalam menggunakan m-payment. Dalam penelitian ini terdapat hipotesis bahwa perceived ease of use dan perceived usefulness merupakan variabel yang memengaruhi attitude toward using dalam menggunakan m-payment; attitude toward using memengaruhi behavior intention to use; perceived usefulness memengaruhi behavior intention to use. Penelitian ini diharapkan dapat memberikan kontribusi yang signifikan tentang penerimaan penggunaan teknologi m-payment. Analisis dengan menggunakan prosedur Partial Least Square (PLS) dimana berkaitan dengan dua langkah utama, yaitu penilaian terhadap pengukuran dan model struktural (Chun, 2015)

\section{Metode}

Penelitian ini menggunakan pendekatan kuantitatif karena data penelitian berupa angka-angka dan analisisnya menggunakan statistik (Sugiyono, 2013). Variabel laten yang digunakan dalam penelitian ini adalah perceived ease of use (EOU), perceived usefulness (PU), attitude toward using (ATU), behavior intention to use (BITU) dengan model penelitian ditunjukkan pada Gambar 3.

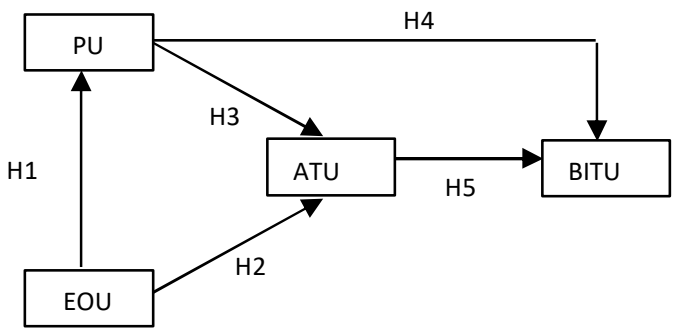

Gambar 3 Model Penelitian

Pengumpulan data dilakukan pada bulan September sampai Desember 2019 melalui pengisian kuesioner secara daring menggunakan Google Form. Terdapat 11 pernyataan dalam kuesioner yang mewakili masing-masing variabel. Dengan penjabaran sebagai berikut:

1. Variabel PU terdiri dari dua pernyataan (PU1 dan PU2).

2. Variabel PEOU terdiri dari empat pernyataan (PEOU1, PEOU2, PEOU3, dan PEOU4).

3. Varibel ATU terdiri dari dua pernyataan (ATU1, ATU2).

4. Variabel BITU terdiri dari tiga pernyataan yaitu (BITU1, BITU2, dan BITU3)

Teknik sampling yang digunakan adalah simple random sampling, dimana setiap anggota dari populasi memiliki peluang sama untuk terpilih menjadi responden sebagai sampel. Populasi penelitian ini adalah pengguna mobile payment dengan aplikasi OVO. Seperti yang telah dijelaskan pada latar belakang, OVO merupakan aplikasi m-payment terbesar saat ini. Analisis data menggunakan PLS tidak membutuhkan jumlah data yang besar, jumlah data kurang dari 100 masih dapat diterima. Penelitian menggunakan data primer dari survei yang dilakukan agar dapat menjawab persoalan penelitian. 
Partial Least Square digunakan dalam menganalisis data sehingga dapat menjelaskan ada tidaknya hubungan antar dua atau lebih variabel laten serta ukuran sampel data yang diperlukan kecil yaitu kurang dari 100. Hipotesis penelitian ini adalah:

1. $\mathrm{H}_{0}$ : ATU tidak berpengaruh signifikan terhadap BITU.

$\mathrm{H}_{1}$ : ATU pengaruh signifikan terhadap BITU.

2. $\mathrm{H}_{0}$ : PEOU tidak berpengaruh signifikan terhadap ATU.

$\mathrm{H}_{1:}$ PEOU berpengaruh signifikan terhadap ATU.

3. $\mathrm{H}_{0}$ : PEOU tidak berpengaruh signifikan terhadap PU.

$\mathrm{H}_{1}$ : PEOU berpengaruh signifikan terhadap PU.

4. $\mathrm{H}_{0}$ : PU tidak berpengaruh signifikan terhadap ATU. $\mathrm{H}_{1}$ : PU pengaruh signifikan terhadap ATU.

5. $\mathrm{H}_{0}$ : $\mathrm{PU}$ tidak berpengaruh yang signifikan terhadap BITU.

$\mathrm{H}_{1}$ : PU pengaruh signifikan terhadap BITU.

\section{Hasil Kerja}

\section{Demografi Responden}

Hasil survei menunjukkan data yang dikumpulkan sejumlah 91 responden, dengan demografi sebagai berikut:

1. Responden berjenis kelamin laki-laki sebanyak $74 \%$ dan sisanya adalah wanita (Gambar 4).

2. $74 \%$ responden berusia $15-25$ tahun, $16 \%$ berusia 26-35 tahun, $8 \%$ berusia 36-45 tahun dan sisanya berusia lebih dari 45 tahun (Gambar 5).

3. $66 \%$ responden berasal dari Surabaya, $15 \%$ berasal dari Tangerang, $12 \%$ berasal dari Jakarta dan sisanya berasal dari kota lainnya (Gambar 6).

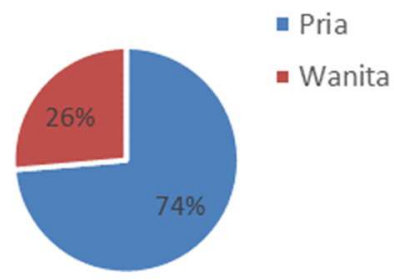

Gambar 4 Responden Berdasarkan Jenis Kelamin

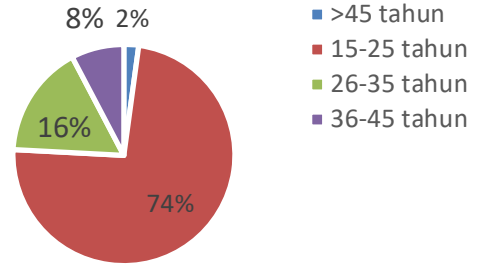

Gambar 5 Responden Berdasarkan Usia

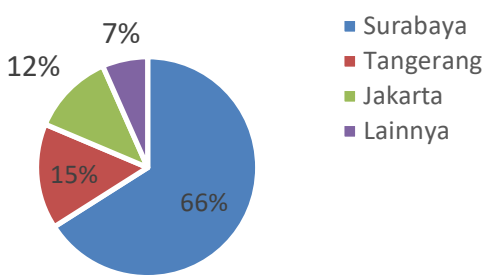

Gambar 6 Responden Berdasarkan Kota

\section{Model Awal}

Model awal yang digunakan pada penelitian ini diambil dari Technology Acceptance Model dengan variabel laten yaitu perceived ease of use (EOU), perceived usefulness (PU), attitude toward using (ATU), dan behavior intention to use (BITU). Model awal (Gambar 7) kemudian dianalisis menggunakan software SmartPLS.

\section{Evaluasi Models of Measurement/Outer Model}

Models of Measurement/Outer Model dilakukan untuk mengetahui hubungan secara langsung indikator dengan variabel laten. Dalam analisis data menggunakan SmartPLS terdapat kriteria yang digunakan untuk menilai outer model yaitu convergent validity, discriminant validity dan composite validity.

Convergent validity dapat dimulai dengan mengevaluasi item reliability (indikator validitas) yaitu berdasarkan nilai loading factor (Gambar 8). Apabila nilai loading factor diatas 0,5 maka dapat dikatakan bahwa indikator tersebut valid untuk mengukur variabel laten (Yamin, 2011) (Tabel 1).

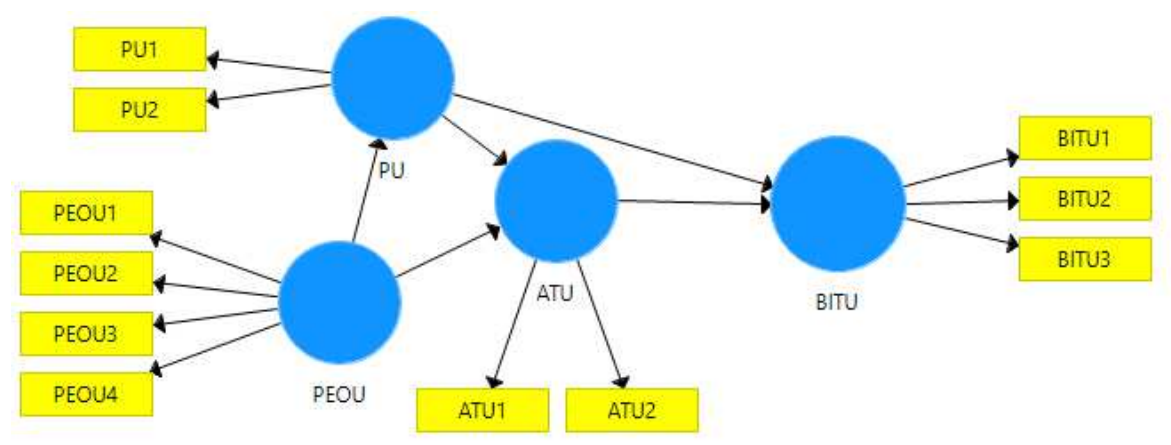

Gambar 7 Model Awal 


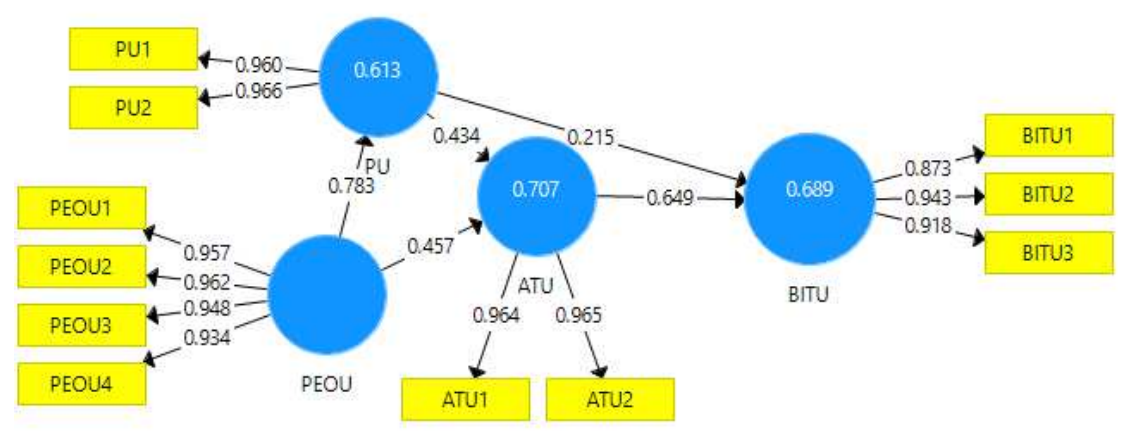

Gambar 8 Loading Factor

Tabel 1 Evaluasi Nilai Loading Factor

\begin{tabular}{lcc}
\hline Indikator & Loading Factor & Keterangan \\
\hline ATU1 & 0,9637 & Valid \\
ATU2 & 0,9647 & Valid \\
BITU1 & 0,8726 & Valid \\
BITU2 & 0,9429 & Valid \\
BITU3 & 0,9176 & Valid \\
PEOU1 & 0,957 & Valid \\
PEOU2 & 0,962 & Valid \\
PEOU3 & 0,948 & Valid \\
PEOU4 & 0,9337 & Valid \\
PU1 & 0,9605 & Valid \\
PU2 & 0,9661 & Valid \\
\hline
\end{tabular}

Pengujian berikutnya adalah construct internal consistency melalui nilai cronbach's alpha, composite reliability dan nilai Average Variance Extracted (AVE). Nilai AVE yang disarankan diatas 0,5 . Hasil construct internal consistency dapat dilihat pada Tabel 2. Nilai cronbach's alpha dan composite reliability yang dihasilkan oleh semua variabel laten mendekati 0,7 dan nilai AVE diatas 0,5 sehingga model pengukuran dapat dinyatakan sudah baik (fit).

Tabel 2 Construct Internal Consistency

\begin{tabular}{lcrrr}
\hline & $\begin{array}{c}\text { Cronbach's } \\
\text { Alpha }\end{array}$ & $\begin{array}{c}\text { Composite } \\
\text { Reliability }\end{array}$ & (AVE) & Keterangan \\
\hline ATU & 0,9243 & 0,9635 & 0,9297 & Baik (fit) \\
PU & 0,8978 & 0,9364 & 0,8309 & Baik (fit) \\
PEOU & 0,9641 & 0,9738 & 0,9030 & Baik (fit) \\
BITU & 0,9225 & 0,9626 & 0,9280 & Baik (fit) \\
\hline
\end{tabular}

Evaluasi discriminant validity dilakukan dengan tujuan mengetahui korelasi setiap indikator terhadap variabel laten. Evaluasi dilakukan dengan melihat hasil uji cross loading dengan tujuan memastikan bahwa setiap konsep dari tiap variabel laten berbeda dengan variabel laten lainnya. Dikatakan memiliki discriminant validity yang baik jika nilai loading dari masing-masing indikator lebih besar dari nilai variabel laten. Hasil evaluasi discriminant validity (Tabel 3) menunjukkan bahwa seluruh indikator memiliki loading factor terbesar di variabelnya masing-masing dan tidak pada variabel yang lain sehingga dapat dikatakan bahwa seluruh indikator valid dalam mengukur variabelnya masing-masing.

\section{Evaluasi Model Struktural (Inner Model)}

Evaluasi model struktural dilakukan untuk memprediksi hubungan antar variabel laten yang dapat dilakukan dengan tiga analisis yaitu $\mathrm{R}^{2}, \mathrm{Q}^{2}$ dan $\mathrm{F}^{2}$. Nilai $\mathrm{R}^{2}$ dapat dilihat pada Tabel 4.

Tabel 3 Nilai Cross Loading

\begin{tabular}{lcccc}
\hline & ATU & BITU & PEOU & PU \\
\hline ATU1 & 0,9637 & 0,7775 & 0,7783 & 0,7574 \\
ATU2 & 0,9647 & 0,8031 & 0,758 & 0,7691 \\
BITU1 & 0,6912 & 0,8726 & 0,6681 & 0,6412 \\
BITU2 & 0,7716 & 0,9429 & 0,7814 & 0,6887 \\
BITU3 & 0,771 & 0,9176 & 0,7375 & 0,6637 \\
PEOU1 & 0,7243 & 0,7506 & 0,957 & 0,7586 \\
PEOU2 & 0,7598 & 0,7823 & 0,962 & 0,7746 \\
PEOU3 & 0,7906 & 0,7702 & 0,948 & 0,7286 \\
PEOU4 & 0,7524 & 0,7416 & 0,9337 & 0,7142 \\
PU1 & 0,7411 & 0,6617 & 0,7295 & 0,9605 \\
PU2 & 0,7827 & 0,7405 & 0,7776 & 0,9661 \\
\hline
\end{tabular}

Tabel 4 Nilai $\mathrm{R}^{2}$

\begin{tabular}{lll}
\hline & R2 & Keterangan \\
\hline ATU & 0,7074 & Kuat \\
BITU & 0,6892 & Moderat \\
PU & 0,6133 & Moderat \\
\hline
\end{tabular}

Selain berdasarkan nilai $\mathrm{R}^{2}$, evaluasi model struktural dapat dilakukan dengan melihat nilai $Q^{2}$. $Q^{2}$ dapat dihitung sebagai berikut: 


$$
\begin{gathered}
Q^{2}=1-\left(1-R^{2}\right) \\
Q^{2}=1-(1-0,03) \\
Q^{2}=0,97
\end{gathered}
$$

Nilai Q2 mendekati nilai 1 sehingga dapat dinyatakan model struktural fit dengan data.

\section{Pengujian Hipotesis}

Pengujian hipotesis dilakukan dengan melakukan evaluasi nilai yang terdapat pada path coefficients

\begin{tabular}{|c|c|c|c|c|c|}
\hline & $\begin{array}{l}\text { Original } \\
\text { Sample } \\
\text { (O) }\end{array}$ & $\begin{array}{l}\text { Sample } \\
\text { Mean } \\
\text { (M) }\end{array}$ & $\begin{array}{l}\text { Standard } \\
\text { Deviatio } \\
\text { n } \\
\text { (STDEV } \\
\text { ) }\end{array}$ & $\begin{array}{l}\text { T } \\
\text { Statisti } \\
\text { cs } \\
(\mid \mathrm{O} / \mathrm{ST} \\
\mathrm{DEV} \mid) \\
\end{array}$ & $\begin{array}{l}\mathrm{P} \\
\text { Valu } \\
\text { es }\end{array}$ \\
\hline $\begin{array}{l}\text { ATU_ } \\
-> \\
\text { BITU }\end{array}$ & 0,6495 & 0,6528 & 0,1103 & 5,8905 & $\begin{array}{r}0,00 \\
00\end{array}$ \\
\hline $\begin{array}{l}\text { PEOU } \\
-> \\
\text { ATU }\end{array}$ & 0,4567 & 0,4581 & 0,1000 & 4,5661 & $\begin{array}{r}0,00 \\
00\end{array}$ \\
\hline $\begin{array}{l}\text { PEOU } \\
->\text { PU }\end{array}$ & 0,7831 & 0,7819 & 0,0625 & $\begin{array}{r}12,528 \\
9\end{array}$ & $\begin{array}{r}0,00 \\
00\end{array}$ \\
\hline $\begin{array}{l}\text { PU -> } \\
\text { ATU }\end{array}$ & 0,4340 & 0,4262 & 0,1095 & 3,9633 & $\begin{array}{r}0,00 \\
01\end{array}$ \\
\hline $\begin{array}{l}\text { PU -> } \\
\text { BITU }\end{array}$ & 0,2151 & 0,2140 & 0,1078 & 1,9952 & $\begin{array}{r}0,04 \\
66\end{array}$ \\
\hline
\end{tabular}
(Tabel 5).

Tabel 5 Path Coefficients

Pengujian hipotesis dengan melakukan evaluasi terhadap nilai t-statistik dan $p$-value. Apabila menggunakan nilai t-statistik, maka nilai signifikansi yang digunakan (two-tailed) t-value 1,65 (significance level= $10 \%$ ). Untuk $\mathrm{H}_{0}$ ditolak apabila t-statistik $>1,65$, sedangkan jika menggunakan probabilitas jika $p$-value $<$ 0,05. Berdasarkan informasi Tabel 5, maka dapat disimpulkan hasil uji hipotesis dapat dilihat pada Tabel 6

Tabel 6 Uji Hipotesis

\begin{tabular}{lrll}
\hline & $\begin{array}{l}\text { T Statistics } \\
(\mid \mathrm{O} / \text { STDEV } \mid)\end{array}$ & \multicolumn{1}{l}{ V Values } & Keterangan \\
\hline $\begin{array}{l}\text { ATU-> BITU } \\
\text { PEOU -> }\end{array}$ & 5,8905 & 0,0000 & $\mathrm{H}_{0}$ ditolak \\
ATU & 4,5661 & 0,0000 & $\mathrm{H}_{0}$ ditolak \\
PEOU -> PU & 12,5289 & 0,0000 & $\mathrm{H}_{0}$ ditolak \\
PU -> ATU & 3,9633 & 0,0001 & $\mathrm{H}_{0}$ ditolak \\
PU -> BITU & 1,9952 & 0,0466 & $\mathrm{H}_{0}$ ditolak \\
\hline
\end{tabular}

\section{Kesimpulan}

Penelitian ini memodifikasi model TAM dengan menambahkan variabal lainnya yang diadopsi dari TRA. Berdasarkan Evaluasi Models of Measurement/Outer Model dan Model Struktural (Inner Model) menunjukkan bahwa model fit dengan data atau dapat menggambarkan fenomena/realitas di lapangan. Hal ini menunjukkan bahwa hasil penelitian ini dapat dinyatakan valid dan reliable.
Semua indikator valid dan reliabel merefleksikan variabel laten. Selain itu hasil pengujian hipotesis menunjukkan attitude toward using pengaruh signifikan terhadap behavior intention to use, perceived ease of use berpengaruh signifikan terhadap attitude toward using, perceived ease of use berpengaruh signifikan terhadap perceived usefulness, perceived usefulness pengaruh signifikan terhadap attitude toward using, perceived usefulness berpengaruh signifikan terhadap behavior intention to use. Hasil dari peneliian ini data digunakan untuk mengetahui penerimaan pengguna atas teknologi m-payment sehingga dapat digunakan untuk merumuskan strategi yang berorietasi pada pengguna.

Penelitian ini masih memiliki keterbatasan sehingga masih dapat dikembangkan kedepannya. Keterbatasan ini menyangkut jumlah data yang dikumpulkan. Penelitian selanjutnya dapat menjangkau lebih banyak responden sebagai sampel dan berbagai subjek aplikasi m-payment yang ada saat ini. Selain itu, model juga dapat dikembangkan dengan mengintegrasikan model TAM, TRA dan Theory of Planned Behaviour.

\section{Ucapan Terima Kasih}

Penulis mengucapkan terima kasih kepada Jurusan Teknik Industri dan Program Profesi Insinyur Universitas Katolik Widya Mandala Surabaya yang memberi dukungan untuk menyelesaikan penelitian ini.

\section{Referensi}

Bailey, A.A. et al., (2017) Mobile payments adoption by US consumers: an extended TAM. International Journal of Retail and Distribution Management, 45(6), pp.626-640.

Chun Kit Lok. (2015) Adoption of Smart Card-Based EPayment System for Retailing in Hong Kong Using an Extended Technology Acceptance Model. Advances in Business Marketing \& Purchasing, Volume 23B, 255466.

Davis, F.D. (1986) A Technology Acceptance Model for Empirically Testing New End-User Information Systems, Massachusetts Institute of Technology, Cambridge, MA.

Ernst and young. (2011) Opportunities for telcos in mobile money: 2011, The growth in mobile payments, February 19, 2014, diunduh dari http://www.ey.com/Publication/vwLUAssets/mobile _money_2011/\$FILE/mobile_money_2011.pdf pada 6 Februari 2019.

Flavian, C., Guinaliu, M. and Lu, Y. (2020). Mobile Payments Adoption - Introducing Mindfulness To Better Understand Consumer Behavior. International Journal of Bank Marketing, Vol. 38 No. 7.

Laucereno, S.F. (2019) Ovo dan GoPay, 2 Fintech Kesayangan Orang Indonesia, diakses dari https://finance.detik.com/moneter/d-4423535/ovo-- 
gopay-2-fintech-kesayangan-orang-indonesia pada 3 Juli 2020.

Liébana-Cabanillas, F., Sánchez-Fernández., J., MuñozLeiva, F. (2014) Antecedents of the adoption of the new mobile payment systems: The moderating effect of age. Computer in Human Behaviour, Vol. 25.

MDI Ventures dan Mandiri Sekuritas Research (2018) Mobile Payments in Indonesia: Race to Big Data Domination. Jakarta: MDI Ventures dan Mandiri Sekuritas.

Phonthanukitithaworn, C., Sellitto, C., Fong , M.WL. (2016) An Investigation Of Mobile Payment (Mpayment) Services In Thailand. Asia-Pacific Journal of Business Administration, Vol. 8 Iss 1.

Shin, D. H. (2009) Towards an understanding of the consumer acceptance of mobile wallet. Computers in Human Behavior, 25(6), 1343-1354.

Morgan, J.P. (2013) Insights from J.P. Morgan. diunduh dari www.jpmorgan.com.

Sianipar, B. (2017) Tren dan Permintaan Baru Pembayaran untuk Optimalisasi "Fintech", diakses dari

https://ekonomi.kompas.com/read/2017/03/07/120 000926/tren.dan.permintaan.baru.pembayaran.untu k.optimalisasi.fintech pada 1 Oktober 2020.

Sugiyono, D. (2013) Metode penelitian kuantitatif kualitatif dan R\&D. Bandung: Alfabeta.

Taejung Kim, Weisheng Chiu (2018) Consumer Acceptance Of Sports Wearable Technology: The Role Of Technology Readiness. International Journal of Sports Marketing and Sponsorship, 20(1):109-126.

Untoro., R. Aria T., Komala Dewi (2013) Pemetaan Produ dan Risiko Pembayaran Bergerak (Mobile Payment) Dalam Sistem Pembayaran di Indonesia. Working Paper. Jakarta: Bank Indonesia.

Yamin, S., Heri Kurniawan (2011) Generasi Baru Mengolah Data dengan Partial Least Square Path Modelling, 4th ed., Akila Susila, Ed. Jakarta: Salemba Infotek. 